\title{
METHODS TO PREVENT SILKEN POWDER COLLAPSING AND CLUSHING DURING STORAGE
}

\author{
S.K. Jabbarova ${ }^{1}$, \\ Bukhara Engineering Technological Institute \\ Bukhara, Uzbekistan \\ I.B. Isabaev ${ }^{2}$ \\ Bukhara Engineering Technological Institute \\ Bukhara, Uzbekistan \\ Sadikov Iskandar Shavkatovich ${ }^{3}$ \\ Head of the Department of Physiology and Pathological \\ Physiology of Bukhara State Medical Institute
}

\begin{abstract}
Annotation. The article is devoted to the current problem of increasing the nutritional value and safety of flour confectionery products. The possibility of using white mulberry powder as a sugar substitute in the formulation of this type of product has been revealed. The analysis of the chemical composition of the powder has been carried out. It has been found to be prone to caking and clumping, making it difficult to dose. The expediency of using additives with a high content of dietary fiber (cellulose) as anti-caking agents has been substantiated. Particular attention is paid to the plant fibers "Sanacel Wheat 90" and "Vitazel", wheat bran and germ product. On the example of two-phase free-flowing systems, the possibility of controlling the structural and mechanical properties of dispersed systems has been proved. The ratio of the ingredients of the mixture was established, proposals for their use in the production of flour confectionery were developed.
\end{abstract}

Key words: flour confectionery, mulberry powder, caking, clumping, anti-caking agents

\section{Introduction}

Flour confectionery products, due to their consumer appeal, are in high demand among the population. However, the use of sucrose in the manufacture of these products leads to the development of a number of diseases, such as diabetes mellitus - 10.0-20\%, cardiovascular diseases - 5.0-15.0\%, obesity - 20.0-30, 0\%, etc. Therefore, it becomes necessary to correct the chemical composition of products while maintaining their traditional consumer properties. This can be achieved by the introduction of substances that are beneficial to health: vitamins, minerals, dietary fiber, amino acids and a decrease in the prescription amount of sugar and fat [1, p. 25-26].

It is especially important to replace sugar with other sweeteners, which can be used as components of plants with an increased sweetness index, which would sharply reduce their dosage without disturbing the structure of the final product.

As such an additive can be used the fruits of white mulberry (here), which are characterized by a high content of natural sugars (up to $22.0 \%$ fructose and glucose) and a low acid content ( $0.1 \%$ phosphoric acid), they also contain malic acid, tannins and pectin substances, vitamins $\mathrm{C}, \mathrm{P}$, carotene, choline. In addition, vitamins B1, B2, PP are supplemented with essential oils and lipids, which are necessary for normal human life. The fruits are used for food purposes, for the manufacture of syrup, flour is prepared from the dried fruit. Due to its high sugar content, flour is very hygroscopic and, when stored in an insufficiently dry room, cakes into a solid mass. Dried mulberry fruits are tasty and replace sugar, they are stored for a long time [2].

It is practically impossible to store mulberry fruits, so it is advisable to dry them and then disperse (grind) for use in the production of flour confectionery. However, even at a moisture content of $10.0 \pm 1 \%$, dried fruits are poorly crushed, the mixture crumples, adheres to the working body of the disperser, has a low degree of flowability and is sticky to the touch. Therefore, research is needed to determine effective grinding methods and to prevent powder caking and clumping during storage. 


\section{Main part}

The caking and clumping of powders is based on the processes of structure formation, due to the spontaneous combination of particles. The consequence of this process is a decrease in flowability, a sharp increase in strength and deterioration of consumer properties, and in extreme cases - a complete loss of powder quality. The solution to this problem is associated with the need to exclude the possibility of the formation of strong structures with phase contacts [3].

A natural and generally accepted method of ensuring the necessary flowability and preventing caking and clumping of hygroscopic powders throughout the entire established shelf life is to reduce water absorption by introducing solid water-insoluble additives that absorb moisture or prevent an increase in the contact area between particles. Inert organic or inorganic substances in the form of finely dispersed powders are used as such anti-caking agents or substances [4]. These requirements are met by natural edible plant fibers (cellulose) as an independent product, and in the composition of raw materials with their high concentration.

The aim of the study was to study the effect of various additives containing dietary fiber on the processes of adhesion and caking (clumping) of mulberry powder during storage.

To achieve this goal, the tasks of obtaining powders enriched with dietary fiber from mulberries with functional and technological properties required for bulk materials are being solved. As anti-caking additives for the investigated mulberry powder (hereinafter TP) were taken: wheat dietary fiber "Sanacel Wheat 90" (PVS), plant fiber "Vitazel" (PBV), wheat bran (PO), wheat germ product (ZPP). In the absence of these additives to improve the dispersion of mulberry fruits, the possibility of using wheat flour of the 1st grade (MPsh.)

Wheat fibers "Sanacel Wheat 90" (dietary fiber) are extracted from fiber-rich parts of wheat, have a high water absorption capacity $(1: 3 \ldots$ 1-7) due to the unique capillary structure of the fibers [5].

Natural plant fibers "Vitazel" (dietary fiber) are produced from the vegetative part of grain crops, fruit or vegetable meal. Water-absorption capacity up to 1:11, inert to any prescription ingredients, heat-stable and cold-resistant [6].

Additives "Sanacel Wheat 90" and "Vitazel" do not have a classification number in the digital codification system of food additives (International Numbering Sisteni-INS), that is, their use does not oblige the manufacturer to put the letter E on the label of finished products [7].

The study used batches of bran and wheat germ product obtained at JSC "Dunyo" (Kashkadarya region, Uzbekistan).

\section{Analyses}

Wheat bran are the most accessible and relatively inexpensive sources of dietary fiber (more than $30.0 \%$ hemicellulose, $10.0 \%$ cellulose, $3.0 \%$ lignin, about $2.0 \%$ pectins), therefore, they are currently receiving considerable attention as an independent product and as an ingredient in composite mixtures. In contrast to the refined preparations "Sanacel Wheat 90" and "Vitazel", the bran contains proteins and minerals, vitamins, complete in amino acid composition. So the protein in bran is $29.0 \%$ more (in terms of dry matter) than in wheat flour of the II grade. The ratio of proteins and carbohydrates is 1.0: 3.5 (optimal 1.0: 4.0), while in flour 1.0: 7.0. The bran contains $0.7 \mathrm{mg} \%$ vitamin B1, $0.25 \mathrm{mg} \%$ - B2, $10.0 \mathrm{mg} \%$ - PP, a significant amount of phosphorus, potassium and magnesium [8, p.58-63; 9, pp. 380-382]. The basis for the choice of wheat germ product was the presence of a high-value protein (ACS for lysine 140\%), minerals, tocopherols, provitamin A, biologically active oil with a high content of essential fatty acids [8, p.63-67; 9, pp. 382389]. It should be noted that in practice one has to deal not with "pure" wheat germs, but with the so-called "germ product" containing up to $60 \ldots 65 \%$ of wheat germs and $35 \ldots 40 \%$ of endosperm fractions, flour and wheat bran [10, p. .sixteen; 11, p.81-84].

Research conducted by N.R. Dzhuraeva and others [12, p.22-27], made it possible to establish that the mass fraction of protein and fat in the germ product is on average 2.4 and 7.8 times higher than the same values in flour of the 1st grade and, accordingly, 2, 1 and 5.3 times - in wallpaper flour; iron - 4.0 and 2.0 times; vitamins - 8.0 and 7.0 times

Another important factor in choosing supplements with a high content of dietary fiber (fiber) is their 
high fat-absorbing capacity, which contributes to the possibility of partial or complete replacement of solid fats with liquid vegetable oils in the formulation of flour confectionery products. Since, despite good technological properties, solid fats are characterized by a high content of trans fatty acids that negatively affect human health, and in liquid vegetable oils the mass fraction of the latter does not exceed $1.5 \%$ of the total fat [13, p.11-15; 14, p.4-7].

The high fat-binding capacity of fiber is due to the unique natural capillary structure of the fibers, which allows retaining fat not only due to functional groups, but also by adsorption [15, p.93-98]. In this case, adsorption occurs not only on the outer, but also on the inner surface of the adsorbent [16, p.56-57].

The studied samples of mulberries met the requirements of SS 976513-2020, wheat bran - Uz SSt 1722: 2010 and wheat germ product - Uz SSt 2928: 2015, and in terms of food safety - SanPiN No. 0283-10 and the recommendations of TR TS $021 / 2011$.

To obtain the powder, mulberries were dried by the air-solar method in a heli-drier manufactured by Hohenheim (Germany) to a moisture content of $10.0 \pm 1.0 \%$. The product was mixed in different proportions with anti-caking agents, then crushed (dispersed) in a laboratory micro-mill LZM-1 to the size of dietary flour (exit from sieve No. 27 no more than 2.0\%, passage of sieve No. 38 - no less than 60.0\%). The appearance of dried mulberry fruits and powder from them is shown in Figure 1.

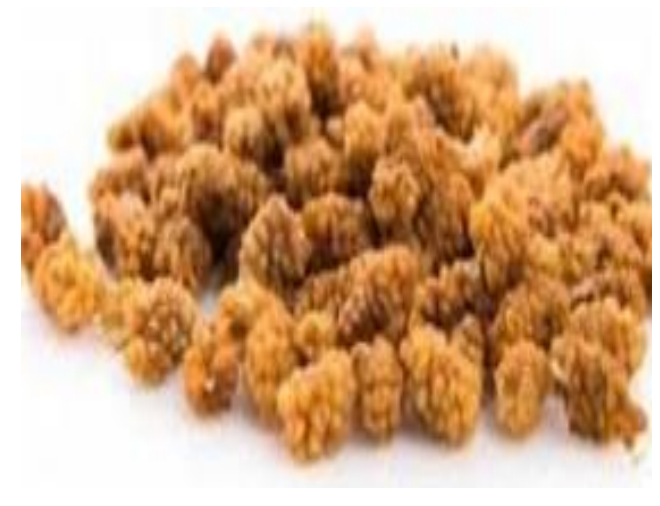

a)

Figure 1. Appearance of the studied raw materials:

dried mulberries (a); mulberry powder (b)

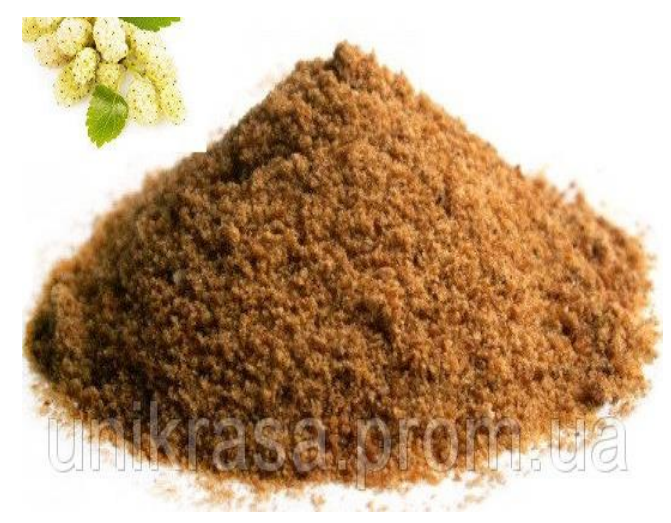

b)

The powder obtained by grinding pre-dried raw materials is large particles of a saturated brown color, heterogeneous in size, it was found that the average particle size of the dominant fraction $(84.0 \%)$ does not exceed 200 microns, have a size of more than 200 microns on average from 4, 2\% of the total number of particles.

Two-phase free-flowing systems were prepared according to the following options:

1 - TP: MPs. - 30:70; 2 - TP: MPs. - 50:50;

3 - TP: PBS - 60:40; 4 - TP: PBS - 70:30; 5 - TP: PBS - 80:20;

6 - TP: PBB - 60:40; 7 - TP: PBB - 20:80;

8 - TP: PO - 30:70; 9 - TP: $\mathrm{PO}-40: 60 ; \quad 10-\mathrm{TP}: \mathrm{PO}-50: 50$;

11- TP: ZPP - 50:50; 12- TP: ZPP - 70:30.

The samples were stored under the same conditions in a sealed glass container at room temperature for 1 month. The research results are shown in Figure 2.

As a result of the studies carried out, it was found that in all variants the dispersion of the product proceeded quite well, no adhesion to the working body and the walls of the mill was observed. However, the following results were obtained by visual inspection of the two-phase mixtures after the expiration of the specified shelf life.

Samples with wheat flour of the 1st grade (MPsh.). In option 1, the mass had a cream color, about $28.0 \%$ of relatively large lumps that did not disintegrate when pressed and $72.0 \%$ of a fine fraction. Option 2 - had a light brown color, the content of large and medium-sized lumps was $74.8 \%$.

Samples with Sanacel Wheat 90 (PVS). In option 3, the entire mass stuck together, when crushed, it 
crumbled into large and medium-sized lumps, the finely dispersed mass averaged $12.4 \%$, the color was light cream. Option 4 - the mass stuck together, when crushed, it crumbled into large and medium-sized lumps, the finely dispersed mass averaged $20.8 \%$, the color was dark brown. Option -5 the mass stuck together, large and medium-sized lumps did not crumble when pressed, the finely dispersed mass averaged $8.4 \%$, the color was dark brown.

Samples with "Vitazel" (PBB). In variant 6, a coalesced light flocculent mass was formed, consisting mainly of large and medium-sized lumps. Option 7 practically did not differ from option 6.

Wheat bran samples (WP). In variant 8 , a homogeneous, well-flowing cream-colored mass without lumps was preserved. Option 9 - the mass sticks together with the formation of up to $80.0 \%$ of large and medium lumps, crumbling when pressed into small lumps, the color is light brown. Option 10 was completely ruined, mold formed on the surface of the mixture, the color was brown.

Wheat germ product (WGP) samples. In option 11, almost the entire mass stuck together and formed a single lump, brown. In variant 12 , the whole mass also stuck together into large lumps that do not crumble when lightly pressed, the color is dark brown.

The obtained results of the study allow us to draw the following conclusions. The use of the studied additives in mixtures with mulberry powder has the following limitations. So, for the direct use of the mixture immediately after grinding in production (without storage), it is possible to use all the additives under study in an amount from 30.0 to $50.0 \%$ by weight of the mixture.

For storage, it is advisable to use only wheat bran in the amount of $70.0 \%$ by weight of the mixture. Recommended shelf life of this mixture is 1 month, allowed at low temperature and relative humidity - 3 months. All other options are ineffective

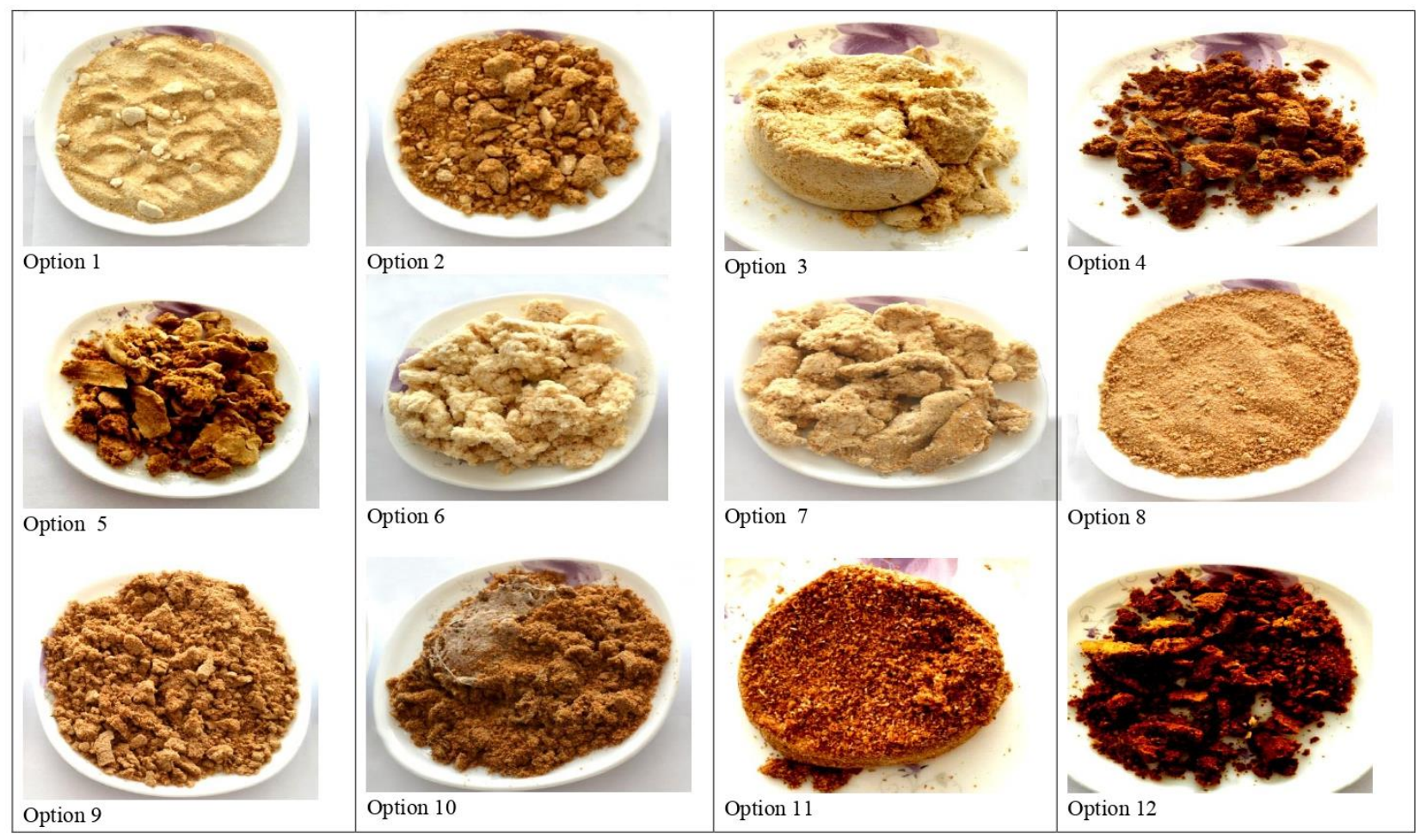

Figure 2. Influence of various additives on caking and clumping of mulberry powder 
The use of bran is preferable, since the additives "Sanacel Wheat 90" and "Vitazel" are not produced in Uzbekistan, therefore the emphasis is on local, relatively cheap and commercially available raw materials.

\section{Conclusion}

Thus, using the example of two-phase free-flowing systems (powdery semi-finished products), the possibility of controlling the structural and mechanical properties of dispersed systems was proved. Considering that in the food industry in various technological processes (including when obtaining a number of viscous-plastic systems, for example, dough) powders are widely used due to the convenience of transportation, storage and dosing, the practical use of the above principles of controlling their properties is very appropriate.

\section{References}

* Lobosova, L.A. Functional confectionery products with non-traditional raw materials / L.A. Lobosova, T.N. Malyutina, M.G. Magomedov, I. G. Barsukova // Modern Science: Actual Problems and Ways to Solve Them. 2013. No. 3. - p. 25-26.

* Mulberry [Electronic resource]. - Access mode: http://webfazenda.ru/ mulberry.html (date of access: 12.12.2018).

* Traceability of powdered materials and methods of its prevention [Electronic resource]. - Access mode: http://hleb-produkt.ru/dispersnye-sistemy/810-slezhivaemost-poroshkoobraznyh-materialov-i-metody-eepredotvrascheniya.html/ (access date: 07/07/2020).

* Additives preventing caking and clumping, baking powder [Electronic resource]. - Access mode: https://prodobavki.com/tags/ dobavki_prepyatstvuyushie_8.html / (date of access: 07/07/2020).

* Wheat dietary fiber "Sanacel Wheat" [Electronic resource]. - Access mode: http://alfagrup.com.ua/katalog/pishevye-volokna-sanacelwheat-200/ (date accessed: 02/07/2020).

* Vitazel [Electronic resource]. - Access mode: http: // moguntia.narod.ru/vita.html/ (date of access: 02/07/2020).

* Classification of food additives [Electronic resource]. - Access mode: http://www.nordspb.ru/article/klassifikaciya-pischevyh-dobavok (date of access: 02/07/2020).

* Drobot V.I. Use of non-traditional raw materials in the baking industry / V.I. Drobot. - K .: Harvest, 1988 .-- 152 p.

* Nilova L.P. Merchandising and examination of grain products: Textbook. - SPb: GIORD, 20005 --- 416 p. Babaev S. D. Determination of the content of the germ in wheat milling products and rational technology of their stabilization / S. D. Babaev // Khleboprodukty. - 2012. - No. 5. - P. 16.

* Babaev SD Determination of the germ content in wheat milling products and rational technology of their stabilization / SD. Babaev // Hleboprodukty.- 2012.-№ 5.- P. 16.

* Vishnyakov AB Wheat germ as a component of compound feed / A. B. Vishnyakov, V. N. Vlasov // Compound feed. - 2011. - No. 2. - p. 81-84.

* Dzhuraeva N.R. Ways of increasing the nutritional value of flour and fat mixtures for nutrition of women in the postpartum period [Text] / N.R. Dzhuraeva [et al.] // Oil and fat industry. - 2016. - No. 5. - p. 22-27.

* Kulakova, S.N. Features of vegetable oils and their role in nutrition [Text] / S.N. Kulakova [et al.] // Oil and fat industry. - 2009. - No. 3. - p. 16-17.

* Livinsky, A.A. Different oils are important, different oils are needed ... [Text] / A.A. Livinsky // Oil and fat industry. - 2011. - No. 2. - p. 4-7.

* Nechaev, A.P. Fatty foods for healthy and therapeutic-and-prophylactic nutrition // International conference "Technologies and healthy food products". Part 1. - M .: publishing house MGUPP, 2003. - p. 93-98.

* Turkova A.Yu. Improving the technology of cooking functional muffins [Text]: dis. ... Cand. tech. Sciences: 05.18.01 / A.Yu. Turkov. - Oryol, 2015 --- 142 p. 